\title{
New approaches in protecting against atherosclerosis in experimental model of postmenopause
}

\author{
Dalia Medhat $^{1 *}$, Mona A. El-Bana ${ }^{1}$, Magdi N. Ashour ${ }^{1}$, Ehsan Badawy ${ }^{1}$, Yasser Diab ${ }^{2}$, Jihan Hussein ${ }^{1}$ \\ ${ }^{1}$ Medical Biochemistry Department, National Research Centre, Doki, Giza, Egypt. \\ ${ }^{2}$ Department of Biochemistry, Faculty of Agriculture, Fayoum University, Egypt.
}

\begin{tabular}{|c|c|}
\hline ARTICLE INFO & ABSTRACT \\
\hline $\begin{array}{l}\text { Article history: } \\
\text { Received on: 02/08/2017 } \\
\text { Accepted on: } 17 / 09 / 2017 \\
\text { Available online: } 30 / 11 / 2017\end{array}$ & $\begin{array}{l}\text { This work is aimed to evaluate the ability of Myrtus communis leaves extract in attenuating endothelial } \\
\text { dysfunction as well as risk of atherosclerosis in ovariectomized rats as a common model of postmenopause. } \\
\text { Total } 60 \text { female albino rats, weighing } 180 \mathrm{~g} \text { were used and assigned to four groups (sham, sham and Myrtus } \\
\text { communis leaves extract, ovariectomized rats (OVX) and ovariectomized treated rats with Myrtus communis }\end{array}$ \\
\hline $\begin{array}{l}\text { Key words: } \\
\text { Myrtus communis leaves } \\
\text { extract, ovariectomized rats, } \\
\text { estrogen, lipoxin A4, fatty } \\
\text { acids, HPLC. }\end{array}$ & $\begin{array}{l}\text { (vWF), interleukin lbeta (IL-1 } \beta \text { ), Lipoxin A4 (LXA4), aortic oxidant and antioxidant in addition to erythrocyte } \\
\text { membrane fatty acids were determined. OVX rats showed a significant increase in inflammatory and oxidant } \\
\text { parameters while, Myrtus communis extract administration ( } 100 \mathrm{mg} / \mathrm{kg} \text { body weight) for two months attenuates } \\
\text { these values in treated group. Myrtus communis leaves extract confirmed our idea in protecting from } \\
\text { atherosclerosis and endothelial dysfunction in ovariectomized rats due to its high content of anti-oxidant and } \\
\text { anti-inflammatory compounds in addition to its high content of } \omega \text { - } 3 \text { fatty acids. }\end{array}$ \\
\hline
\end{tabular}

\section{INTRODUCTION}

Atherosclerosis and its complications are a great global challenge. Coronary artery diseases are the main cause of mortality worldwide. Myocardial infarction or stroke and atherosclerosis are lethal consequences that cause morbidity which related to heart failure resulting from ischemic heart disease or neurological impairment due to stroke (Go et al., 2014). Postmenopausal women are more susceptible to cardiovascular disease than in age-matched premenopausal women. Estrogen vasoprotective actions include activation of nitric oxide production and decreased in vascular smooth muscle cell proliferation while menopause are associated with atherogenic risk factors such as hyperlipidemia, hypertension, obesity, and insulin resistance (Akishita, 2004).

* Corresponding Author

E-mail address: dalia_8383 @ hotmail.com (Dalia Medhat)
Inflammation is the main key player in atherosclerosis from the formation of lesions to the incidence of a coronary take place. Chronic vascular inflammatory mechanism is related to the endothelial ability to release pro-inflammatory cytokines, such as Interleukin-1 (IL-1) and tumor necrosis factor alpha (TNF- $\alpha$ ) that produced by the endothelium, stimulating adhesion molecules and increasing vascular risk (Teixeira et al., 2014).

Nitric oxide (NO) controls the proliferation of vascular smooth muscle cell and reduced the expression of endothelial leukocyte adhesion molecules and the deposition of lipids. Endothelial dysfunction appears to inhibit the biological activity of NO leading to increases in the expression of pro-thrombotic factors, pro-inflammatory adhesion molecules, chemotactic factors, cytokines that stimulate the expression of monocyte chemotactic protein-1 (MCP-1), which recruits monocytes and other chronic inflammatory cells. Monocytes and macrophages were important factors in the development of atherosclerotic lesions (Demir et al., 2012). 
Several studies used food derived anti-oxidant and antiinflammatory properties as chemopreventive agents in many diseases including diabetes (Hussein et al., 2012), osteoporosis (El-Khayat et al., 2010) and liver injury (Hussein et al., 2016a).

Myrtus communis is a recognized medicinal plant and traditionally applied for treatment of urethritis, diarrhea, peptic ulcers, hemorrhoids, inflammation, bleeding, headache, palpitation, leucorrhoea, epistaxis, conjunctivitis, excessive perspiration, pulmonary and skin diseases (Jabri et al., 2016). Myrtus communis essential oil and all extracts from its leaves, branches, fruits and flowers are rich in terpenoid compounds including 1,8- cineole, $\alpha$-pinene, myrtenyl acetate, limonene, linalool and $\alpha$-terpinolene (Wannes et al., 2010; Berka-Zougali et al., 2012). The leaves also rich in tannins and flavonoids (Akin et al., 2010).

AlsoWannes and Marzouk (2016), reported that the fatty acid content of Myrtus communis oil offers the lipids as a valid source of polyunsaturated fatty acids (PUFA) and clarified the usefulness of PUFA in ameliorating heart diseases, inflammation, autoimmune disorders, atherosclerosis, diabetes, and other diseases.

\section{AIM OF THE WORK}

This study aimed to evaluate the ability of the natural supplement of plant origin (Myrtus communis leaves extract) to attenuate endothelial dysfunction as well as atherosclerosis complications in ovarecotmized rats as a suitable model for postmenopausal women.

\section{MATERIALS AND METHODS}

\section{Materials}

Chemicals

Fatty acids standards (HPLC grade), Sigma-Aldrich (St. Louis, MO, USA). Chloroform, methanol and ethyl ether all are HPLC grade and were purchased from (ALDRICH,Germany).

\section{Experimental animals}

Sixty female albino rats, weighing $180 \pm 20 \mathrm{~g}$ from Animal House, National Research Centre (NRC), Giza, Egypt. Rats were individually kept in clean cages of polypropylene and maintained in controlled room temperature with light and dark cycle, given a standard diet and water ad libitum along the experimental period. The experiment was carried out in accordance with guidelines and protocol approved by the Institutional Animal Ethics Committee of National Research Centre (NRC), Giza, Egypt.

\section{Methods}

\section{Myrtus communis alcoholic extract}

Myrtus communis leaves were collected, identified, air dried, powdered and extracted at $28 \pm 2^{\circ} \mathrm{C}$ by the method described by Messaoud et al. (2012).

\section{Ovariectomy Surgical Procedure}

The ovariectomy and sham operations were done according to the method described by Goseki et al. (1995).

Experimental design

Rats were assigned to four groups (15 rats each) as follow:

Group (I): Sham group: Healthy rats were sham-operated and received a vehicle.

Group (II): Sham + Myrtus communis group: sham rats receive alcoholic extract of Myrtus communis in a dose of $100 \mathrm{mg} / \mathrm{kg}$. b.w. daily for two months by stomach tube.

Group (III): OVX group: Rats were surgically ovariectomized and receive a vehicle.

Group (IV): Treated group: OVX rats received alcoholic extract of Myrtus communis in a dose of $100 \mathrm{mg} / \mathrm{kg}$ daily for two months by stomach tube.

After the end of experimental period (two months), animals were kept fasting overnight (12 hour). Under anesthetic blood withdrawn in heparinized tubes; centrifuged at $3000 \mathrm{rpm}$ using cooling centrifuge (Laborzentrifugen, 2K15, and Sigma, Germany). Plasma was separated and stored at $-20{ }^{\circ} \mathrm{C}$ for biochemical analysis. Packed RBCs were used for determination of cell membrane parameters. Aorta from each rat was removed quickly; washed with ice-cold saline and used for determination of oxidant and antioxidant parameters.

\section{Determination of lipid profile}

Cholesterol and high density lipoprotein (HDL) were measured according to Allain et al. (1974).Triglycerides was measured according to Glick et al. (1986). Low density lipoprotein (LDL) was calculated from the equation mentioned by Ahmadi et al.(2008).

\section{Determination of aortic nitric oxide (NO)}

Aortic NO level was estimated according to Moshage et al. (1995).

\section{Determination of aortic superoxide dismutase (SOD); catalase (CAT) and malondialdehyde (MDA)}

Aortic SOD and CAT activities were determined according to the method described previously (Nishikimi et al., 1972 \& Johansson and Bory, 1988) respectively and MDA was determined colorimetrically as described before (Uchiyamara et al., 1978).

\section{Determination of total protein}

Total protein in tissue was estimated using BICON Kit diagnostic, Germany according to Passing and Balok (1993). 
Plasma estrogen, asymmetric dimethylarginine (ADMA), interleukin 1 beta $(I L-1 \beta)$, Lipoxin A4 and von Willebrand factor $(v W F)$

Were estimated by Enzyme-linked immunosrbent Assay (ELISA) according to the manufacturer's protocols (R\&D systems) according to Taddei et al. (1996), Deanfield et al. (2007), David et al., (2011) and Raitakari et al. (2000) respectively.

\section{Erythrocyte membrane fatty acids}

Erythrocyte membrane fatty acids (FA) were fractionated and analyzed by high performance liquid chromatography (HPLC) according to El-Khayat et al. (2013). Briefly, cell membrane was homogenized in $2 \%$ acetic acid / ethyl ether mixture (2:1 volume ratio). The solution mixed well using vortex and centrifuged at $3000 \mathrm{rpm}$, the organic phase was evaporated (under nitrogen gas stream) to dryness; the residue was dissolved in $500 \mu \mathrm{l}$ acetonitrile and filtered by PVDF $0.45 \mu \mathrm{m}$ filter before injection onto HPLC.

\section{HPLC Condition}

Fatty acids were determined using reversed phase HPLC, column ODS $(250 \mathrm{X} 4.6 \mathrm{X}$ particle size $5 \mu \mathrm{l})$ and mobile phase acetonitrile / water mixture (70/30) v/v by isocratic elution with flow rate $1 \mathrm{ml} / \mathrm{min}$. UV detector adjusted at $200 \mathrm{~nm}$ wave length. Different concentrations of each standard were estimated by HPLC and their peak areas were determined. Standard curve was constructed by plotting peak areas versus the corresponding concentrations. The concentrations in samples were obtained from the standard curve.

\author{
Statistical Analysis \\ All data were expressed as mean \pm SE. Statistical \\ significance was tested by one way analysis of variance \\ (ANOVA)
}

\section{RESULTS}

Results of this study revealed that cholesterol and triglycerides levels were significantly increased in OVX group compared to $\mathrm{SH}$ group; whereas the treatment by Myrtus communis significantly decreased these parameters in treated group compared to the OVX group. On the other hand, plasma HDL-cholesterol was significantly decreased in OVX group compared to $\mathrm{SH}$ while this value was significantly increased in treated group compared to OVX group (table :1).

Ovariectomized rats showed a significant decrease in aortic NO,SOD and CAT and a significant increase in MDA level compared to $\mathrm{SH}$ group while in treated group there was a significant increase in aortic SOD and CAT accompanied by a significant decrease in MDA level compared to OVX group (table : 2).

Our results indicated that in OVX group there was a significant decrease in plasma estrogen and LA-4 levels concomitant with a significant increase in plasma ADMA, vWF and IL-1 $\beta$ levels. However Myrtus communis supplementation significantly increased plasma estrogen and LA-4 and decreased levels of ADMA, vWF and IL-1 $\beta$ in treated group compared to OVX group (table:3).

Table 1: Plasma lipid profile in different studied groups.

\begin{tabular}{lcccc}
\multicolumn{1}{c}{ Groups } & SH & SH + Myrtus communis & OVX & Treated \\
Parameters & & & $125.8^{a} \pm 4.0$ & $50.6^{a, b} \pm 0.3$ \\
Cholesterol (mg/dl) Mean \pm SE & $110 \pm 0.4$ & $93.2 \pm 0.6$ & $89.2^{a} \pm 1.0$ & $60.1^{a, b} \pm 0.5$ \\
Triglyceride (mg/dl) Mean \pm SE & $95.1 \pm 1.4$ & $71.7^{a} \pm 0.60$ & $21.6^{a} \pm 6.7$ & $34^{a, b} \pm 2.7$ \\
HDL-Cholesterol (mg/dl) Mean \pm SE & $78.8 \pm 9.5$ & $74.6 \pm 7.2$ & $86.4^{a} \pm 1.0$ & $36.4^{a, b} \pm 0.98$ \\
LDL-cholesterol (mg/dl) Mean \pm SE & $24.8 \pm 1.3$ & $20.1 \pm 0.45$ & &
\end{tabular}

Significant value $\leq 0.05$

$P^{a}$ value compared to SH group, $P^{b}$ value compared to ovariectomized group.

Table 2: Aortic Nitric oxide (NO), Superoxide dismutase (SOD), Catalase (CAT) and Malondialdehyde (MDA) in different studied groups

\begin{tabular}{|c|c|c|c|c|}
\hline Groups & SH & SH + Myrtus communis & OVX & Treated \\
\hline SOD activity (U/mg protein) Mean \pm SE & $11.1 \pm 0.6$ & $12.1 \pm 0.8$ & $7.6^{\mathrm{a}} \pm 2.1$ & $16.7^{\mathbf{a}, \mathbf{b}} \pm 0.2$ \\
\hline MDA level (nmol/mg protein) Mean \pm SE & $0.31 \pm 0.03$ & $0.29 \pm 0.01$ & $0.63^{\mathrm{a}} \pm 0.05$ & $0.5^{\mathrm{a}, \mathrm{b}} \pm 0.06$ \\
\hline
\end{tabular}

Significant value $\leq 0.05$

$P^{a}$ value compared to $\mathrm{SH}$ group, $P^{b}$ value compared to Ovariectomized group.

Table 3: Plasma estrogen, ADMA, vWF, IL-1 $\beta$ and lipoxin-A4 levels in different studied groups

\begin{tabular}{|c|c|c|c|c|c|}
\hline Parameters & Groups & SH & SH +Myrtus communis & OVX & Treated \\
\hline ADMA $(\mu \mathrm{mol} / \mathrm{L})$ Mean \pm SE & & $3.36 \pm 0.4$ & $2.86 \pm 0.7$ & $4.2^{\mathrm{a}} \pm 0.8$ & $3.0^{\mathbf{a}, \mathbf{b}} \pm 0.85$ \\
\hline $\mathrm{vWF}(\mathrm{ng} / \mathrm{L})$ Mean $\pm \mathrm{SE}$ & & $534.0 \pm 62.0$ & $510.0 \pm 40.0$ & $753^{a} \pm 30.3$ & $610.0^{\mathbf{a}, \mathbf{b}} \pm 40.0$ \\
\hline $\mathrm{LA}-4(\mathrm{Pg} / \mathrm{L})$ Mean $\pm \mathrm{SE}$ & & $88 \pm 2.0$ & $90 \pm 2.3$ & $64^{\mathrm{a}} \pm 2.1$ & $129^{\mathbf{a}, \mathrm{b}} \pm 4.7$ \\
\hline
\end{tabular}

LA-4 $(\mathrm{Pg} / \mathrm{L})$ Mean $+\mathrm{SE}$

Significant value $\leq 0.05$.

$P^{a}$ value compared to $\mathrm{SH}$ group, $P^{b}$ value compared to ovariectomized group. 
Table 4: Erythrocyte membrane fatty acids in different studied groups.

\begin{tabular}{|c|c|c|c|c|}
\hline Parameters & SH & SH + Myrtus communis & OVX & Treated \\
\hline AA (mg /ml RBCs) Mean \pm SE & $0.05 \pm 0.004$ & $0.05 \pm 0.008$ & $0.19^{a} \pm 0.001$ & $0.06^{a, b} \pm 0.001$ \\
\hline LA (mg /ml RBCs) Mean \pm SE & $0.73 \pm 0.03$ & $0.68 \pm 0.03$ & $0.85^{a} \pm 0.04$ & $0.73^{a, b} \pm 0.02$ \\
\hline ALA (mg /ml RBCs) Mean \pm SE & $0.48 \pm 0.008$ & $0.68 \pm 0.015$ & $0.49 \pm 0.03$ & $0.69^{b} \pm 0.02$ \\
\hline
\end{tabular}

Significant value $\leq 0.05$.

$P^{a}$ value compared to $\mathrm{SH}$ group, $P^{b}$ value compared to ovariectomized group.

Results of this study indicated that there was a significant increase in erythrocyte membrane arachidonic acid (AA) and linoleic acid (LA)along with a significant decrease in $\alpha$-linolenic acid (ALA) in OVX group compared to SH group while administration of myrtle significantly attenuated these levels in treated group compared to OVX group (table :4).

\section{DISCUSSION}

Menopause is a significant risk factor for cardiovascular diseases (CD) that were considered one of the main reasons of mortality and morbidity in women (Demir et al., 2012). Estrogen plays an important role in cardio-protective mechanism, thus it reduces LDL level in addition to its antioxidant properties in lipids oxidative degradation (Subbiah, 2002).Oxidation of LDL in the vessel wall appears to be the first step in lipid deposition on the arterial wall (Østerud and Bjørklid, 2003). Oxidized LDL (oLDL) is a chemotactic agent that increases the flow of monocytes and macrophages into the endothelium which rapidly evolve into lipid laden foam cells of an atheromatous plaque (Singh et al., 2002).

In this study, it was observed that OVX rats showed a significant decrease in plasma estrogen level accompanied by significant increase in plasma cholesterol, triglycerides and LDL levels, in addition to a significant decrease in HDL-cholesterol compared to sham group. Also Yung et al. (2011) demonstrated that increase cardiovascular hazard is associated with estrogen insufficiency that characterized by atherogenic modulation of plasma lipid profile, stimulation of the renin-angiotensin system and excess production of reactive oxygen species (ROS) which affects nitric oxide (NO) as was found in the current study.Also, Rossouw et al. (2002) suggested that increased levels of total cholesterol and LDLwere associated with atherosclerosis lesions in human and animals.Estrogen affects lipoprotein and triglyceride profiles in such a way that indirectly influences atherosclerosis as well as more direct affects the vascular endothelium through estrogen receptors. The most important effect of estrogen was through estrogen receptor alpha (ER- $\alpha$ ) which stimulates endothelial nitric oxide synthase and promote endotheliumdependent relaxation (Mitchell et al., 2005).

Our results indicated that there was a significant increase in ADMA level accompanied by a significant decrease in aortic nitric oxidein OVX group compared to the sham group indicates endothelial dysfunction.Several studies suggested a positive correlation between ADMA and cholesterol levels. ADMA exhibited a positive association with LDL cholesterol; LDL oxidation in the vascular wall may be responsible for the effect of this lipoprotein on ADMA elevation, through inhibition of dimethylarginine dimethylaminohydrolases (DDAH) activity (Landim et al., 2009). Kitova et al. (2007) demonstrated that endogenous nitric oxide synthetase (eNOS) activation decreased in hypercholesterolemic patients, resulting in alteration of endothelium-dependent vasodialation and decreased adhesion of platelets and monocytes, these events were related to the elevation of ADMA levels, which was a competitive inhibitor of eNOS, thus LDL cholesterol increases the expression of ADMA precursor protein and also inhibits the activity of DDAH enzyme, which degrades ADMA. In addition, activation of eNOS is controlled by estrogen via modulation of the eNOS/caveolin-1 (Cav-1) complex formation while in menopause, which was accompanied by loss of estrogen and inactivation of estrogen receptors, it correlates with a reduction in eNOS expression (Loyer et al., 2007).

Elevation of vWF level which secreted from endothelial cells and released into the circulation plays functional roles in homeostasis through mediating platelet adhesion to the vascular wall and appeared to be strongly associated with major cardiac events (Kucharska-Newton et al., 2009). It was associated with the increase in LDL and atherogenesis (van Galen et al., 2012).Our results confirmed these suggestions, we found elevation in LDL and $\mathrm{vWF}$ levels in OVX group. Our data revealed that in ovariectomized rats there was a significant decrease in erythrocyte membrane ALA along with increase in AA and LA compared to sham group. Alterations in the composition of erythrocyte membrane fatty acid, specifically $\omega-3$, were a significant indication of increased cardiovascular risk. In agreement, Harris et al. (2007) indicated that, low levels of plasma n-3 PUFA is strongly correlated to vascular inflammation, endothelial activation and increase of coronary heart disease in postmenopausal women. Recently, Hussein et al. (2016b) suggested that increasing n-3 fatty acids in ovarictomized rats decrease both production and releasing of pro-inflammatory cytokines such as IL-1 $\beta$ as was found in our study. Contrarily, n-6 fatty acids have the opposite effect.

In the current study, a significant increase in IL- $1 \beta$ along with a significant decrease was observed in LXA4 in OVX group compared to the sham group. Concomitant with our results Hussein et al. (2016b) indicated that experimental OVX was followed by osteoporotic features participating in activation of osteoblastic causing release of pro-inflammatory cytokines like IL6, IL-1 and TNF- $\alpha$. The correlation between estrogen and inflammatory cytokines was demonstrated by Compston (2001). Estrogen decreases bone resorption directly via inhibiting 
osteoclasts and indirectly via suppressing osteoplastic production of various proresorptive paracrine factors such as IL-1b, IL-6, and TNF- $\alpha$. In addition estrogen reduces the degree of inflammation and tissue damage by decreasing the expression of the inflammatory markers and inhibiting their reaction (Faloni et al., 2007). Lipoxins (LX), the products of arachidonic acid metabolism, were produced through sequential lipoxygenase activity. LXA4 affects endothelial cells by the stimulation of cytoprotective pathways (Fiorucci et al., 2003). It upregulates the expression of heme-oxygenase 1 (HO-1), which is responsible for the inhibition of cellular activation, including decreased expression of adhesion molecules (Nascimento-Silva et al., 2005).Also LXA4 inhibits pro-inflammatory cytokine and reactive oxygen species (ROS) generation in addition to suppression of NAD (P) $\mathrm{H}$ oxidase-mediated ROS generation in endothelial cells (Gozzelino et al., 2010).It was reported that, inflammatory diseases were characterized by neutrophil infiltration, release of proinflammatory cytokines such as TNF- $\alpha$ and IL-1 $\beta$ and bioactive mediators e.g., leukotrienes (LTs) and prostaglandins, and expression of adhesion molecules [intercellular adhesion molecule (ICAM)-1 and Pselectin] ; these mediators are involved in tissue damage (Fialkow et al., 2007). In addition, the increase in concentration of intracellular $\mathrm{Ca}^{2}$ leads to a production of proteases (e.g., leukocyte elastase or cathepsin G) and formation of ROS (Parekh and Penner,1997), which destroy invading particles and damage cells and tissues of the host. Moreover, ROS generation induced by intracellular $\mathrm{Ca}^{2}$ elevation caused lipid peroxidation and DNA single-strand damage (Pérez-De La Cruz et al., 2008).Concomitant with our results, Muthusami et al.(2005) indicated the increase of LPO and $\mathrm{H}_{2} \mathrm{O}_{2}$ levels and decrease in antioxidants enzymes such as SOD, GPx and GST in OVXrats compared to sham-operated control group. Endothelial dysfunction results in increasing the pro-inflammatory and prothrombotic phenotype of the endothelium and thus induce attachment and subsequent migration of leukocytes, events that were associated with the commencement of the formation of atherosclerotic lesion (Landmesser et al., 2004). Taken together, these findings suggest that ovariectomy caused systemic inflammation and increasing in free radicals that is related to the progression of atherosclerotic lesion.

In this study, administration of Myrtus communis extract significantly attenuated inflammation and oxidative stress. Myrtus communis is a vital aromatic species with medicinal benefits from the Myrtaceae family and was traditionally used in several diseases due to its antioxidant and anti-inflammatory properties (Aleksic et al., 2013).The antioxidant function of Myrtus communis was due the active compounds in its essential oil and phenolic fraction that contribute to the overall antioxidant and anti-mutagenic potential. The ROS scavenger activity and inhibition of the expression adhesion molecules expression of Myrtus communis was mainly related to the interaction with intracellular $\mathrm{Ca}$ signaling. In addition, it had a direct effect on oxidative enzymes that induced the antioxidant enzyme activities, reduced lipid peroxidation and, scavenge free radicals (Rosa et al.,2008 \& El-Bana et al., 2017). Myrtus communis inhibits the synthesis of eicosanoids through suppression of 5-lipoxygenase, cyclooxygenase-1and inhibition of elastase and ROS production via inactivation of receptor-coupled camobilization (Feisst et al., 2005). Sepici et al. (2004) reported that plant extract rich in polyunsaturated fatty acids (PUFA) such as myrtle had an important role in reliving cardiovascular diseases, inflammation, atherosclerosis and other diseases. It was postulated that n-3 PUFAs hypotriglyceridemic properties including, decrease synthesis of TG and saturated fatty acids through the reduction of hepatic sterol regulatory element-binding protein 1, acetyl-CoA carboxylase 1, fatty acid synthase, and diacylglycerol acyltransferase 2. In agreement, our results indicated the attenuation of fatty acids disturbance in ovarictomized rats by supplementation of Myrtus communis extract. Increasing danger of cardiac events was negatively correlated with blood and tissue content of $\omega$-3 fatty acids (Harris et al., 2007). Beneficial roles of PUFA include enhanced vasodilatation through keeping the balance between vasoconstrictor and vasodilator endotheliumderived factors, activation and of cyclooxygenase- 2 expression, inhibition of nuclear factor kappa $\mathrm{B}$, reduction of expression of endothelial adhesion molecules, suppression of leukocyte adhesion to endothelial cells (Kris-Etherton et al., 2003) and modulation of oxidative stress (Harris et al., 2007).

\section{CONCLUSION}

We concluded that Myrtus communis extract could be a promising source of natural anti-oxidants, anti inflammatory and omega-3 fatty acids that attenuates the risk of endothelial dysfunction and atherosclerosis in an experimental model of postmenopausal women.

\section{ACKNOWLEDGMENT}

Financial support and sponsorship: Authors are thankful for National Research Centre Cairo, Egypt for carrying out this work and funding this project no. 10010310.

Conflict of Interests: There are no conflicts of interest.

\section{REFERENCES}

Ahmadi SA, Boroumand MA, Moghaddam KG, Tajik P and Dibaj SM. The Impact of Low Serum Triglyceride on LDL-Cholesterol Estimation. Arch Iranian Med. 2008; 11 (3): 318 - 321.

Akin M, Aktumsek A, Nostro A. Antibacterial activity and composition of the essential oils of Eucalyptus camaldulensis Dehn. and Myrtus communis L. growing in Northern Cyprus. Afr J Biotechnol. 2010; 9 (4): 531-535.

Akishita M. Atherosclerosis and Hyperlipidemia. Hormone Replacement Therapy. 2004; 47(4): 175-178.

Aleksic V and Knezevic P. Antimicrobial and antioxidative activity of extracts and essential oils of Myrtus communis L. Microbiological Research. 2013; 169 (4): 240-254.

Allain CC, Lucy S, Poon S, Cicely G, Chen W, Richmed Paul CF. Enzymatic determination of total cholesterol. Clinical Chemistry. 1974; 20: 470-475.

Berka-Zougali B, Ferhat MA, Hassani A, Chemat F, Allaf KS. Comparative study of essential oils extracted from Algerian Myrtus 
communis L. leaves using microwaves and hydrodistillation. Int J Mol Sci. 2012; 13: 4673-4695.

Compston, JE. Sex steroids and bone. Physiolog Rev. 2001; 81(1): 419-47.

David MP, Ellen G. Fiona CD, Henry NJ, Jane EN. A role for lipoxin A4 as anti-inflammatory and proresolution mediator in human parturition. FASEB J. 2011; 25: 569 -575.

Deanfield JE, Halcox JP, Rabelink TJ. Endothelial function and dysfunction: testing and clinical relevance. Circulation. 2007; 115:128595.

Demir BÇ, Uyar Y, Özbilgin K and Köse C. Effect of raloxifene and atorvastatinin atherosclerotic process in ovariectomized rats :Atherosclerotic process of menopause", Journal of Obstetricsand Gynaecology Research. 2012; 39(1): 229-236.

El-Bana MA, Medhat D, Ashour MN, Diab Y, Hussein J. Myrtus communis extract attenuates atherosclerosis in streptozotocin - induced diabetic rats. Bioscience Research. 2017; 14(2): 257-264.

El-khayat Z., Abo el-matty, D., Rasheed, W., Hussein, J., Shaker, O. and Raafat, J. Role of cell membrane fatty acids in insulin sensitivity in diabetic rats treated with flaxseed oil. international journal of pharmacy and pharmaceutical sciences. (2013) 5 (2): 146-151.

El-Khayat Z, Rasheed W, Ramzy T, Hussein J, Agaiby M, Morsy S, Morsy F, and Shaffie N. Protective effect of garlic oil against liver injury in experimental animals. Journal of Medicinal Plants Research. 2010; 4 (22), 2359-2369.

Faloni AP, Sasso-Cerri E, Katchburian E, Cerri PS. Decrease in the number and apoptosis of alveolar bone osteoclasts in estrogen-treated rats. J Periodontal Res. 2007; 42(3): 193-201

Feisst C, Franke L, Appendino G, Werz O. Identification of molecular targets of the oligomeric nonprenylated acylphloroglucinols from Myrtus communis and their implication as anti-inflammatory compounds. J Pharmacol Exp Ther. 2005; 315 (1), 389-396.

Fialkow L, Wang Y, and Downey GP. Reactive oxygen and nitrogen species as signaling molecules regulating neutrophil function. Free Radic Biol Med. 2007; 42: 153-164

Fiorucci S, Distrutti E, Mencarelli A, Morelli A, Laufor SA, Cirino $\mathrm{G}$, et al. Evidence that 5-lipoxygenase and acetylated cyclooxygenase 2-derived eicosanoids regulate leukocyte-endothelial adherence in response to aspirin Br J Pharmacol. 2003; 139: 1351-1359.

Glick MR, Ryder KW, Jackson SA. Graphical comparisons of interferences in clinical chemistry instrumentation. Clin Chem. 1986; 32: 470-474.

Go AS, Mozaffarian D, Roger VL, Benjamin EJ, Berry JD, Blaha MJ, Dai S, Ford ES, Fox CS, Franco S, Fullerton HJ, Gillespie C, Hailpern SM, Heit JA, Howard VJ, Huffman MD, Judd SE, Kissela BM, Kittner SJ, Lackland DT, Lichtman JH, Lisabeth LD, Mackey RH, Magid DJ, Marcus GM, Marelli A, Matchar DB, McGuire DK, Mohler ER, Moy CS, Mussolino ME, Neumar RW, Nichol G, Pandey DK, Paynter NP, Reeves MJ, Sorlie PD, Stein J, Towfighi A, Turan TN, Virani SS, Wong ND, Woo D, Turner MB: American Heart Association Statistics Committee and Stroke Statistics Subcommittee. Executive summary: heart disease and stroke statistics update: a report from the American Heart Association. Circulation. 2014; $129: 399-410$.

Goseki S, Omi M, Oida N, Ezawa S, Sasaki S. Voluntary exercise increases osteogenetic activity in rat bones. Bull. Tokyo Med. Dent. Univ. 1995; 42, 1-8.

Gozzelino R, Jeney V, Soares MP. Mechanisms of cell protection by heme oxygenase-1 Annu Rev Pharmacol Toxicol. 2010; 50: 323-354.

Harris WS, Poston WC, Haddock CK. Tissue n-3 and n-6 fatty acids and risk for coronary heart disease events. Atherosclerosis. 2007; $193: 1-10$.

Hussein J, Abo Elmatty D, Medhat D, Mesbah N, Abdel Razik F. and Fahmy H. Flaxseed oil attenuates experimental liver hepatitis. Der Pharmacia Lettre. 2016a; 8 (8):142-150.

Hussein J, Ashour M, Rasheed W, Medhat D, El-Banna M, Morsy $\mathrm{S}$ and Youness E. Marine n-3 fatty acids attenuate pro- inflammatory mediators in ovariectomized rats as a model of postmenopausal. Der Pharmacia Lettre. 2016b; 8 (8):250-254.

Hussein J, El-Khayat Z, Taha M, Morsy S, Drees E and Khateeb S. Insulin resistance and oxidative stress in diabetic rats treated with flaxseed oil. Journal of Medicinal Plants Research.2012; 6(42): 54995506

Jabri MA, Tounsi H, Rtibi K, Marzouki L, Sakly M. and Seba H. Ameliorative and antioxidant effects of myrtle berry seed (Myrtus communis) extract during reflux-induced esophagitis in rats Pharmaceutical Biology. 2016; 54 (9), 1575-1585.

Johansson LH and Borg LA. A spectrophotometric method for determination of catalase activity in small tissue samples. Analytical Biochemistry. 1988; 174,33 1-336.

Kitova LV, Terzieva D, Nikolov F, Mateva N. Asymmetric dimethylarginine in hypercholesterolemic patients. Journal of IMAB 2007; 13(1): 133-142.

Kris-Etherton PM, Harris WS, Appel LJ. Fish consumption, fish oil, omega-3 fatty acids, and cardiovascular disease. 2003; 107:512.

Kucharska-Newton AM, Couper D.J., Pankow, J.S., Prineas, R.J., Rea, T.D., Sotoodehnia, N., et al. Hemostasis, inflammation, and fatal and nonfatal coronary heart disease: long-term follow-up of the atherosclerosis risk in communities (ARIC) cohort. Arterioscler Thromb Vasc Biol. 2009; 29(12):2182-90.

Landim, MBP, Filho AC, and Chagas ACP. Asymmetric Dimethylarginine (ADMA) and Endothelial Dysfunction: Implications for Atherogenesis.Clinics (Sao Paulo). 2009; 64(5): 471-478.

Landmesser U, Hornig B. and Drexler H. Endothelial function: a critical determinant in atherosclerosis? Circulation . 2004; 109 (1): II27II33.

Loyer X, Damy T, Chvojkova Z, Robidel, E, Marotte F, Oliviero $\mathrm{P}$, et al. 17betaestradiol regulates constitutive nitric oxide synthase expression differentially in the myocardium in response to pressure overload. Endocrinology. 2007; 148(10): 4579-84.

Messaoud C, Laabidi A, Boussaid M. Myrtuscommunis L.;Journal of Food Science. 2012; 77: Nr. 9.C941-C 947.

Mitchell WC, Weiping F, Hong C, Ramesh P, Peter HL, Alan BL, Qizhi Y, Changyi C. Effects of progesterone and estrogen on endothelial dysfunction in porcine coronary arteries. Journal of surgical research. 2005; 124(1): 104-111.

Moshage $\mathrm{H}$, Kok B, Huizenga Jr. Nitrite and nitrate determinations in plasma: a critical evaluation.Clin. Chem. 1995; 41, $892-$ 896.

Muthusami S, Ramachandran I, Muthusamy B, Vasudevan G, Prabhu V, Subramaniam V, Jagadeesan A, Narasimhan S. Ovariectomy induces oxidative stress and impairs bone antioxidant system in adult rats Clin Chim Acta. 2005; 360(1-2):81-6.

Nascimento-Silva V, Arruda MA, Barja-Fidalgo C, Villela CG, Fierro IM. Novel lipid mediator aspirin-triggered lipoxin A4 induces heme oxygenase-1 in endothelial cells Am J Physiol Cell Physiol. 2005; 289: C557-C563.

Nishikimi M, Roa NA, and Yogi K. Determination of superoxidedismutase.Res. Commun. 1972; 46:849-854.

Østerud B, Bjørklid E. Role of Monocytes in Atherogenesis. Physiological Reviews. 2003; 83(4):1069-1112.

Parekh AB and Penner R. Store depletion and calcium influx. Physiol Rev. 1997; 77: 901-930.

Passing H, Balok WA. New biometrical procedure for testing the equality of measurements from two different analytical methods. J clin biochem. 1993; 21:709-720.

Pérez-De La Cruz V, Konigsberg M, Pedraza-Chaverri J, Herrera-Mundo N, Díaz-Muñoz M, Morán J, Fortoul-van der Goes T, Rondán-Zárate A, Maldonado PD, Ali SF et al. Cytoplasmic calcium mediates oxidative damage in an excitotoxic/energetic deficit synergic model in rats. Eur J Neurosci . 2008; 27:1075-1085,

Raitakari OT and Celermajer DS. Testing for endothelial dysfunction. Ann Med. 2000; 32:293-304.

Reira L, Teixeira-de-Lemos E, Pinto F, Parada B, Mega C, Vala H, Pinto R, Garrido P, Sereno J, Fernandes R, Santos P, Velada I, Melo A, Nunes S, Teixeira F, Reis F. Effects of sitagliptin treatment on 
dysmetabolism, inflammation, and oxidative stress in an animal model of type 2 diabetes (ZDF rat).Mediators Inflamm. 2010; 1-11.

Rosa, A., Melis, M.P., Deiana, M., Atzeri, A., Appendino, G., Corona, G., et al.Protective effect of the oligomeric acylphloroglucinols from Myrtus communis on cholesterol and human low density lipoprotein oxidation. Chem Phys Lipids. (2008)155 (1), 16-23.

Rossouw JE, Anderson GL, Prentice RL, et al. Risks and benefits of estrogen plus progestin in healthy postmenopausal women: principal results from the Women's Health Initiative randomized controlled trial. Jama. 2002; 288:321-33.

Sepici A, Gurbuz I, Cevik C, Yesilada E. Hypoglycaemic effects of myrtle oil in normal and alloxan-diabetic rabbits. J Ethnopharmacol. 2004; 93 (2-3), 311-318.

Singh RB, Mengi SA, Xu YJ, Arneja AS and Dhalla NS. Pathogenesis of atherosclerosis: A multifactorial process. Exp Clin Cardiol. 2002; 7(1): 40-53.

Subbiah MTR. Estrogen replacement therapy and cardioprotection: mechanisms and controversies. Braz J Med Biol Res. 2002; 35(3): 271-276.

Taddei S, Virdis A, Ghiadoni L, Mattei P, Sudano I, Bernini G et al. Menopause is associated with endothelial dysfunction in women. Hypertension. 1996; 28(4): 576-82.

Teixeira BC, Lopes AL, Rodrigo CO and Cleiton SC. Inflammatory markers, endothelial function and cardiovascular risk. J Vasc Bras. 2014; 13(2):108-115.

Uchiyamara M, Mihara M. Determination of malondialdehyde in tissue by thiobarbituric acid test. Analytical Biochemistry. 1978; 86:271-278. van Galen KPM, Tuinenburg A, Smeets EM and Schutgens REG. Von Willebrand factor deficiency and atherosclerosis. Blood Reviews. 2012; 26(5): 189-196.

Wannes WA and Marzouk B. Characterization of myrtle seed (Myrtus communis var. baetica) as a source of lipids, phenolics, and antioxidant activities. Journal of Food and Drug Analysis . 2016; 24(2): 316-323.

Wannes WA, Mhamdi B, Sriti J, Jemia MB, Ouchikh O, Hamdaoui G, Kchouk ME, Marzouk B. Antioxidant activities of the essential oils and methanol extracts from myrtle (Myrtus communis var. italica L.) leaf, stem and flower. Food Chem Toxicol. 2010; 48, 13621370 .

Yung LM, Wong WT, Tian XY, Leung FP, Yung LH, Chen ZY et al. Inhibition of renin-angiotensin system reverses endothelial dysfunction and oxidative stress in estrogen deficient rats. PLoS One. 2011; 6 (3):e1743

\section{How to cite this article:}

Medhat D, El-Bana MA, Ashour MN, Badawy E, Diab Y, Hussein J. New approaches in protecting against atherosclerosis in experimental model of postmenopause. J App Pharm Sci, 2017; 7 (11): 090-096. 